\title{
Análise de Eficiência Solar em Painéis Fotovoltaicos
}

\author{
Gabriel V. Barbosa, Matheus F. S. Alcântara, Matheus R. G. Araújo, \\ Tiago T. Fonseca, Rosemberg F. N. Rodrigues \& Márcio J. Dias
}

A energia elétrica vem se tornando a cada dia mais indispensável para sobrevivência humana, pois vivemos uma sociedade dependente das tecnologias e que buscam melhorias constantes. Dessa forma, a busca por maior produção de energia limpa e sustentável ao meio ambiente cresce de uma maneira agressiva, partindo desse princípio a energia eólica (força do vento), energia solar (irradiação solar) apresenta uma proposta de energia alternativa, contribuindo assim para preservação do meio ambiente. Este trabalho teve como objetivos encontrar as condições ideias, por meio de estudos da melhor posição dos módulos de produção em uma residência familiar do município de Vianópolis-Goiás. A metodologia utilizada foi realizar medições das produções em intervalos de uma hora (07h às $18 \mathrm{~h})$, entre os dias 16/09/2019 a 20/09/2019, alterando o ângulo de inclinação de fixação dos módulos. Os dados foram tratados estatisticamente com o auxílio de software para demonstrar os resultados graficamente. Os painéis analisados foram de material policristalino da empresa Byd Company Limited com potência máxima 330 W. Após a análise estatística dos dados, foi evidenciado que os resultados que apresentaram melhores posicionamento foram das placas no sentido norte, com inclinação $16^{\circ}$ sendo também observado que a maior produção foi correspondida entre o período compreendido entre $11 \mathrm{~h}$ às $13 \mathrm{~h}$.

Palavras-chave: energia; eficiência; fotovoltaica.

Electricity hasbe come increas inglyin dispensable for humans urvival, because welive in a technology-dependent society that seeks constantim provements. Thus, thesearch for greater production of clean and sustainable energy tothe environment grow saggressively, starting from this principle windenergy (wind force), solar energy (solar irradiation) presents analternative energy proposal, thus contributing to the preservation of the environment. This work aimed to find the ideal conditions, through studies of the best position of production modules in a family residence in the municipal it yof Vianópolis-Goiás. The methodology used was to perform me asurements of production sat interval so fone hour (07:00 to 18:00 hours), between 16/09/2019 and 09/20/2019, changing the angle of attachment inclination of the modules. The data were statistically treated withtheaid of software to demonstrate the results graphically. The panel sanaly zed werepoly cry stalline material of byd company limited with maximum power $330 \mathrm{~W}$. After statistical analysis of the data, it was evidenced that the results that presented better positioning were of the plates in thenorth directio.

Keyword: energy; efficiency; photovoltaic. 


\section{Introdução}

Com o aumento gradativo do consumo de energia, diversos métodos são explorados a fim de obter um rendimento sustentável. Diante disso, as fontes de energias renováveis conseguem suprir toda essa necessidade, devido ao fato de seus recursos serem abundantes no planeta Terra, além de não degradar o meio ambiente, tendo como principais fontes de energias renováveis: oceânicas, geotérmica, biomassa, hídrica, eólica e solar.

A energia solar se destaca por ter um potencial maior do que os outros processos, apresenta crescimento rápido e altos níveis de investimento envolvido, tendo seu recurso (irradiação) disponível e de fácil acesso em diversos países. Além disso, podem ser instalada tanto em grandes demandas, quanto pequenas, a relação espaço eficiência é ótima devido ao fato de não utilizar muito espaço, tornando-a assim mais compacta.

A conversão de raios solares em eletricidade é feita efetuada de duas formas, uma pelo efeito fotovoltaico em que os fótons contidos na luz através da excitação dos elétrons quando a luz entra em contato com o material do módulo e se transforma em energia, e com o efeito termoelétrico em que a transformação se obtém pela a diferença de potencial de dois metais com determinadas condições.

Para um rendimento de máxima eficiência do módulo fotovoltaico, devem-se observar as variáveis presentes no processo de captação da energia solar, entre elas, a irradiação no local ao decorrer do tempo, o posicionamento correto em relação ao Sol com a sua face voltada ao norte, o ângulo de instalação onde varia de acordo com a latitude local, a escolha do material do módulo que age diretamente para determinação da eficiência desejada. Em residências e comércios a frequência de instalação de painéis tem sido cada vez maior, para que despesas sejam menores, além desse investimento obter um retorno rápido.

O objetivo do trabalho é observar o desempenho dos painéis em diferentes residências, analisando a eficiência gerada em diferentes ângulos de inclinação e posicionamento, afim de identificar em qual condição se encontra a melhor produção em painéis fotovoltaicos fixos.

\section{Revisão Bibliográfica}

A energia fotovoltaica é uma junção proveniente da obtenção de uma energia renovável sendo ela a solar, em que por meio de um processo de transição passado pelas placas solares, irá transformá-la em uma energia que poderá ser aproveitada. A energia fotovoltaica vem se tornando viável para grandes empresas onde há um processo maior e para lugares onde não tem chegado facilmente energia elétrica ${ }^{1}$. A Figura 1 representa o esquema básico de captação de energia solar, desde a produção no painel fotovoltaico a distribuição por meio da corrente alternado.

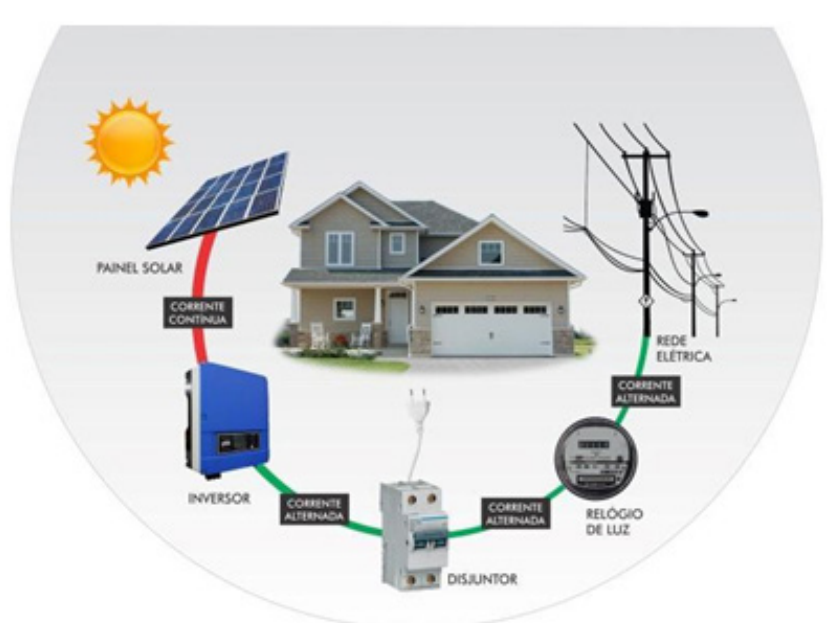

Figura 1: Modelo esquemático da construção de energia em uma casa. Fonte: Layer Solar. Sistema

Este tipo de energia renovável tem se tornado uma grande aliada na diminuição da energia comum produzida por hidrelétricas, pois anda lado a lado no modo de produção sustentável, e tem impacto direto na diminuição de poluentes produzidos no processo de obtenção de energia ${ }^{1}$.

\section{PRODUÇÃO DE ENERGIA FOTOVOLTAICA}

Os efeitos da radiação (calor e luz) sobre materiais semicondutores ou silício, fazem a conversão direta de energia 
solar para energia elétrica, são destacados os com efeitos fotovoltaico e termelétrico. Sendo o primeiro que os fótons contidos na luz solar são transformados em energia elétrica, através da excitação dos elétrons dos materiais com presença de luz. E no segundo e a junção de dois metais causando uma diferença de potencial em determinadas condições².

De acordo com o físico francês Edmund Bequerel, o princípio do funcionamento de uma célula fotovoltaica é através do fotoelétrico, na qual a energia luminosa é absorvida por elétrons do material, tendo em vista que um tipo certo de material pode ser melhor condutor do que outros materiais, apresentando princípio visíveis em gráficos ${ }^{3}$.

Praticamente todas células fotovoltaicas que têm uma tensão de fato é desenvolvida, que se tem uma incorporação uma junção PN num semicondutor. A Figura 2 representa a junção PN e a parte principal dessa célula, em que a porção de recepção de luz é material do tipo $\mathrm{N}$ na peça e abaixo o material e de tipo $\mathrm{P}$, tendo o material $\mathrm{P}$ com falta de elétrons e o material $\mathrm{N}$ com um número excessivo de elétrons. Devido a essa diferença os elétrons da camada $\mathrm{N}$ fluem para a camada $\mathrm{P}$ formando um campo elétrico, conhecido também como barreira de potência, e que se tem uma grade e uma base metálica, onde é feita a coleta da corrente elétrica produzida pela a ação de luz ${ }^{3-7}$.

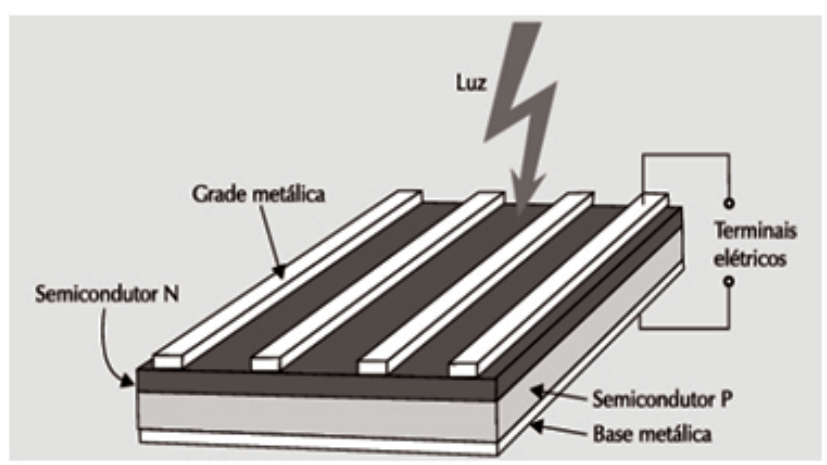

Figura 2: Esquema da captação de energia solar. Fonte: Energia solar fotovoltaica: Conceitos e Aplicações (2012)
Conforme a Ministério de Minas e Energia (MME), o Brasil possuía, ao final de 2016, 81 MWp de energia solar fotovoltaica instalados, o que vem a representar cerca de $0,05 \%$ da capacidade instalada total no país. Do total de 81 MWp existentes em 2016, 24 MWp correspondiam à geração centralizada e $57 \mathrm{MWp}$ à geração distribuída ${ }^{2}$.

As células de silício monocristalino são frutos de uma produção em fornos especiais e possui uma eficácia na conversão da luz solar em eletricidade, superior a $12 \%$. Já as células de silício poli cristalino proporciona uma eficiência pouco menor que as de monocristalino (entre $10 \%$ a $11 \%){ }^{10}$

As placas fotovoltaicas agem diretamente de acordo com as suas condições de funcionamentos ambientais, dentre elas magnitude da irradiação solar, temperatura, ângulo de inclinação, dentre outras. Para uma performance melhor diante da sua eficiência energética, o ângulo de inclinação dos painéis e o tipo de módulo são parâmetros fundamentais ${ }^{8}$.

A Eficiência da energia fotovoltaica se deve diretamente, do aproveitamento da energia gerada pelo Sol, em que as placas transformam essa luz recebida em energia elétrica, utilizando dessa fonte como alternativa energética mais promissora de transformação de energia. Essa energia solar apesar de ser um meio alternativo, pode ser não ser uma solução completa para produção de energia'.

Contudo, os painéis fotovoltaicos apresentam perdas significativas, causadas pelo efeito da massa de ar atmosférica, no inversor de frequência e no armazenamento de energia. Desta forma, apresentando uma regularidade de manutenção nessas variáveis, a perda pode ser diminuída, aumentando assim o seu ganho energético? .

A baixa utilização de energia solar no Brasil deve ser sinal de atenção, pois possui expressivo potencial para geração de energia elétrica a partir da fonte solar, contando com níveis de irradiação solar maiores que demais países onde possui uma infraestrutura disseminada, como Alemanha, França e Espanha ${ }^{10}$.

A preocupação com a geração de energia por fontes renováveis vem sendo questão de debate nos últimos tempos pois no ano de 2015, o Brasil assumiu um compromisso de 
redução de emissões de gases em 2025 e 2030, resultando em $43 \%$ em relação aos níveis de $2005^{11}$.

\section{EFEITOS DO USO DA ENERGIA RENOVÁVEL X ENERGIA ELÉTRICA}

A energia fotovoltaica é uma junção proveniente da obtenção de uma energia renovável solar, por meio de um processo de transição passado pelas placas solares, que irá transformá-la em uma energia que poderá ser aproveitada. Com a obtenção deste tipo de energia, o retorno não poderá ser viável financeiramente, pois necessita de um grande poder aquisitivo a curto prazo sendo remunerado apenas em longo prazo. Apesar de o custo ser um pouco demasiado, a energia fotovoltaica vem se tornando viável para grandes empresas onde possuem um processo maior e para lugares onde não tem chegado facilmente energia elétrica.

Este tipo de energia renovável tem se tornado uma grande aliada na diminuição da energia comum produzida por hidrelétricas, pois anda lado a lado no modo de produção sustentável, e tem impacto direto na diminuição de poluentes produzidos no processo de obtenção de energia ${ }^{1}$.

\section{IRRADIAÇÃO}

A radiação solar e a energia total incidente sobre a superfície da Terra, onde sua carga depende da posição no tempo e latitude local, isso se tem devido ao movimento de rotação e de translação. Com esses fatos há uma variação de duração solar do dia em períodos do ano e regiões. Sendo uma inesgotável fonte de energia, com um potencial enorme de utilização na captação e conversão em outras formas de energia, para ter seu máximo aproveitamento deve se ajustar o coletor ou painel solar em uma posição seguindo a latitude e o período do ano onde necessita de mais energia, a Figura 3 mostra as a média anual de horas de insolação diária no Brasil2:

A radiação também e dependente das condições climáticas e atmosférica, com a reflexão e absorção de raios solares pela a atmosfera da Terra, radiação solar tem somente uma parte em contato com a superfície terrestre,

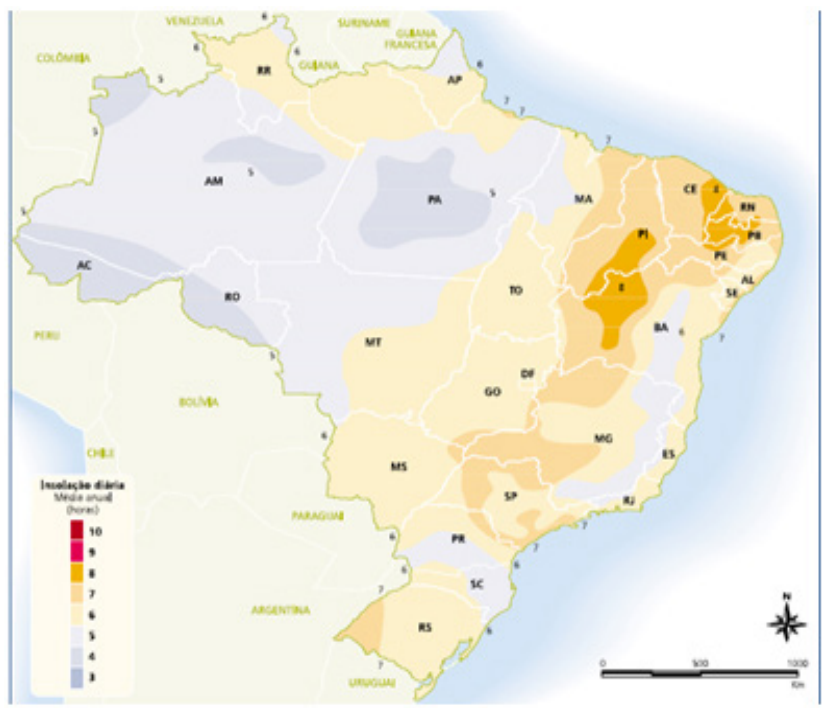

Figura 3: Distribuição da insolação diária no Brasil. Fonte: Aneel. Energia solar ${ }^{10}$.

e estima-se que a atmosfera terrestre recebe por ano $1,5 \mathrm{x}$ $10^{9} \mathrm{TWh}$ de energia solar, e seu consumo mundial anual e 10 mil vezes menor da quantidade incidente na superfície ${ }^{5}$.

\section{INSTALAÇÃODOS PAINÉIS SOLARES}

A composição de um painel solar contém um ou mais módulos fotovoltaico que estão conectados eletricamente, em que cada um é composto por diversas células fotovoltaicas individuais, integrado com hardware de balanço de sistema (BOS), tendo com componentes inversores, estantes, desconexões, compartimentos, fiação e transformadores, a função de transformadores, inversores e combinadores e converter a corrente contínua de baixa voltagem em alta tensão de corrente alternada ${ }^{5}$.

Há dois tipos de sistemas solar o on grid eo off grid, a grande diferença e que o off grid e autônomo e não necessita ser ligado a uma rede de energia, enquanto o on grid não se sustenta sozinho e tem que ser conectado a uma rede local ${ }^{10}$.

\section{POSICIONAMENTO E ÂNGULO}

Módulos fotovoltaico sem um sistema de rastreamento solar, tem sua melhor orientação defina em direção 
norte, devido ao Sol nascer no leste e se pôr no oeste, e com o decorrer do ano a altura solar tem alterações em cada estação, tendo o norte com maior contato com os raios solares durante o decorrer do dia e do ano, como é apresentado nas Figuras 4 (a) e 4 (b) ${ }^{12}$.
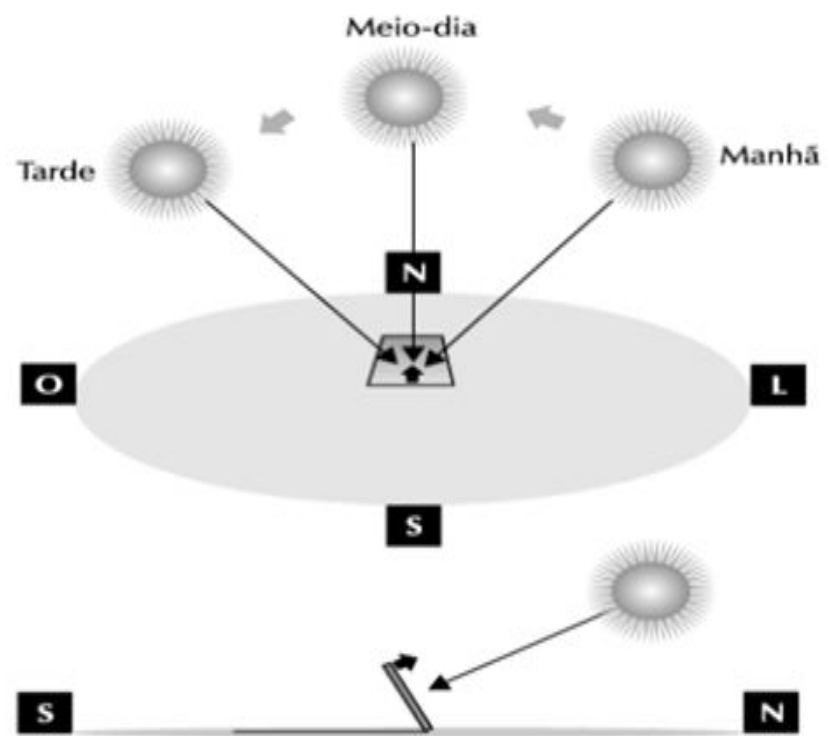

Figura 4 (a): Posição do Sol relativo aos pontos cardeais.

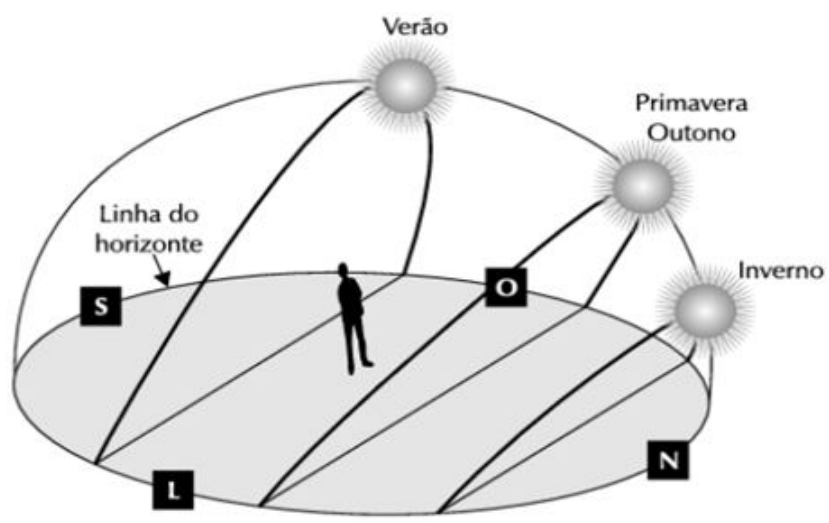

Figura 4 (b): Posição do Sol relativo as 4 estações. Fonte: Energia solar fotovoltaica: Conceitos e Aplicações (2012)
Os raios solares incidentes na superfície terrestre variam ao longo do dia, mostrado na Figura 5, um módulo que está instalado com um ângulo de inclinação $\alpha$ em relação a solo e com a face virada para o norte ${ }^{12}$.

\section{$\alpha$ Ângulo de inclinaçăo do paine \\ $\beta$ Ângulo de incidência do raio solar \\ $\mathbf{r}_{s}$ Ângulo da altura solar}

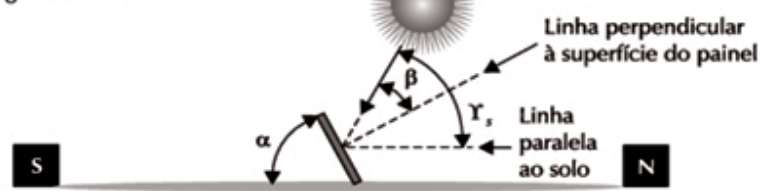

Figura 5: Módulo com ângulo de inclinação. Fonte: Energia solar fotovoltaica: Conceitos e Aplicações (2012)

Oângulo de incidência solar no módulo solar e representado pela sigla $\beta$, e definido uma linha reta traçada perpendicular à superfície do módulo, sendo que a passar dos dias a ocorrendo uma variação em relação à altura solar $\Upsilon$ s, fazendo que a o ângulo dado pela incidência solar seja diferente ${ }^{16}$.

O melhor aproveitamento dos raios solares tem-se quando $\mathrm{o}$ ângulo $\beta=0$, devido à incidência estar a linha perpendicular ao módulo, tendo assim a máxima captação da energia solar, por isso a inclinação do módulo deve ser ajustada em relação à altura $\Upsilon$ s solar do dia, mas maior parte dos módulos fotovoltaicos são instalados com ângulo fixo, então deve-se ser escolhido esse ângulo usando algum critério ${ }^{12}$.

\begin{tabular}{|c|c|}
\hline Latitude Geográfica do local & Ângulo de inclinação recomendado \\
\hline $0^{\circ}$ a $10^{\circ}$ & $\alpha=10^{\circ}$ \\
\hline $11^{\circ}$ a $20^{\circ}$ & $\alpha=$ latidude \\
\hline $21^{\circ}$ a $30^{\circ}$ & $\alpha=$ latidude $+5^{\circ}$ \\
\hline $31^{\circ}$ a $40^{\circ}$ & $\alpha=$ latidude $+10^{\circ}$ \\
\hline $41^{\circ}$ ou mais & $\alpha=$ latidude $+15^{\circ}$ \\
\hline
\end{tabular}

Quadro 1: Representação do ângulo de inclinação em relação à latitude geográfica. Fonte: Energia solar fotovoltaica: Conceitos e Aplicações (2012)

O critério mais utilizado se dá pela latitude do local onde se está sendo instalado o painel para que se tenha uma boa produção de energia ao longo do ano, a Tabela apresentada mostra um ângulo recomendado para certas latitudes, não se recomenda ângulo menor que $10^{\circ}$ por ocorrer acúmulo de poeira nas placas ${ }^{12}$. 


\section{TRACKER OU SEGUIDOR SOLAR}

O seguidor solar ou tracker é um dispositivo que faz que os painéis fiquem em uma posição favorável para captar o máximo de irradiação diária. Com isso, sua produção de energia seja maior, sendo utilizado com frequência em usinas fotovoltaicas, podendo aumentar seu desempenho na produção cerca de $28 \%$ onde existe abundância em incidência solar e $16 \%$ onde não se tem, apesar de acrescentar cerca de $20 \%$ no custo total de um sistema de geração fotovoltaica ${ }^{13}$.

\section{Metodologia}

A pesquisa foi desenvolvida no município de Vianópolis, em cinco residências com ângulo e posicionamento diferentes, que tinham instaladas painéis fotovoltaicos da empresa Byd Company Limited, tipo de módulo é BYD335PHK-36, avaliado com potência máxima (Pmáx) de $335 \mathrm{~W}$, tensão de circuito aberto de $45,44 \mathrm{~V}$ e de Pmáx de $38,10 \mathrm{~V}$, com corrente de curto circuito de $9,25 \mathrm{~A}$ e para Pmáx $8,79 \mathrm{~A}$, a temperatura normal de operação e de $45^{\circ} \mathrm{C}$ com variação de $2^{\circ} \mathrm{C}$. Os módulos têm dimensão de 1992 x 992 x $35 \mathrm{~mm}$, com o peso de 22,2 kg, sua célula e 4 Bus Bar Solar HalfCeel 156,75 x 78,735mm, estrutura de liga de alumínio anodizado e com o vidro frontal temperado de 3,2 $\mathrm{mm}$ com revestimento de AR.

Devido o experimento ocorrer na mesma região a irradiação é uma variável que não sofre alteração de um módulo para outro, sendo ela considerada por um média $5,422 \mathrm{kWh} / \mathrm{m}^{2}$ por dia. A potência elétrica resulta pela multiplicação da tensão e corrente, e a eficiência do sistema depende do ângulo de inclinação e do posicionamento em relação ao Sol, então para fazer uma análise expressiva dos dados aplicou as três variáveis.

Para ter o desempenho dos sistemas fotovoltaicos coletou-se a potência dos módulos em intervalo de duas horas, então os horários foram: $9 \mathrm{~h}, 11 \mathrm{~h}, 13 \mathrm{~h}, 15 \mathrm{~h}$ e 17h. Utilizou quatro sistemas de monitoramento que acompanhavam os painéis através de seus inversores, foram eles: Canandian, Growatt, Fronius, Solar View.

\section{Resultados}

Os gráficos a seguir são representações dos dados colhidos durante a semana nas respectivas residências, nos períodos de 9h, 11h, 13h, 15h, 17h. Foram coletadas a potência elétrica por módulo e total, ângulo de inclinação, quantidade de painéis, direcionamento em relação ao Sol.

A primeira residência obtinha de 10 módulos, todos posicionados para o norte, com um ângulo de inclinação de $14^{\circ}$, apresentando uma média de $183,30 \mathrm{~W}$, com seu monitoramento efetuado pelo sistema Canandian. Sua média foi de $183,30 \mathrm{~W}$, o dia que maior apresentou potência foi o dia 16/09/2019 com média de 194,84W sendo a maior potência elétrica gerada de $256,472 \mathrm{~W}$ às $13 \mathrm{~h}$, conforme o Gráfico 1 a seguir representa:

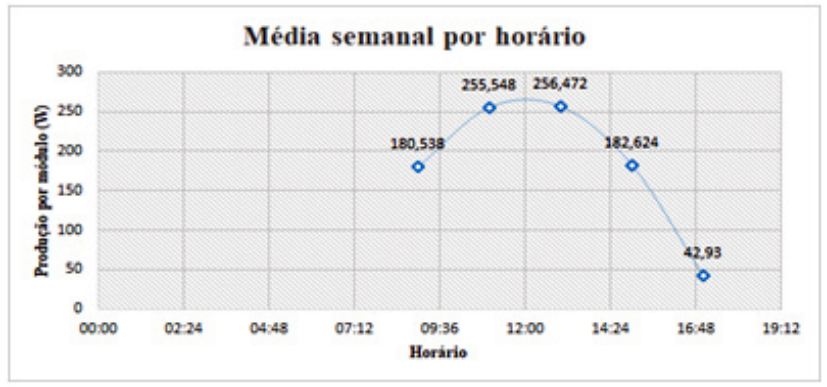

Gráfico 1: Coleta dos dados da Produção da energia gerada na residência 1. Fonte: Autores

O Gráfico 2, faz parte da segunda residência, fez parte um sistema de 90 módulos fotovoltaicos, sendo 24 apontados para o norte, 16 para o sul e 50 para o leste. O ângulo de inclinação é de $9^{\circ}$ para todos os painéis, para acompanhamento foi utilizado o sistema de monitoramento da Canandian. A média de potência gerada do módulo para os dias analisados foi de $172,28 \mathrm{~W}$, com o maior no dia $16 / 09 / 2019$ com $184,11 \mathrm{~W}$ e média maior às $11 \mathrm{~h}$ com valor de $254,133 \mathrm{~W}$. 


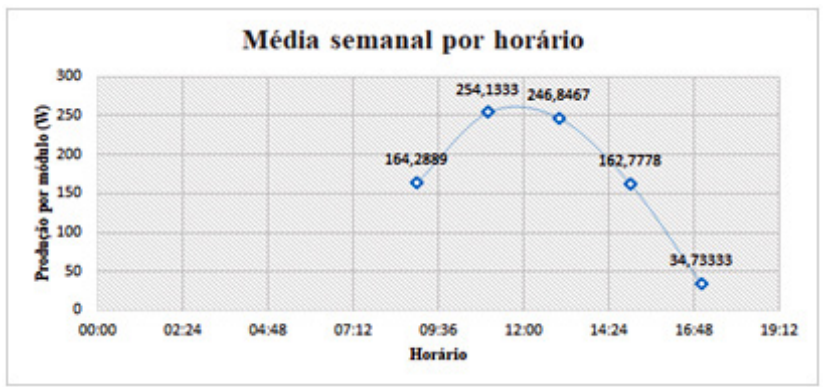

Gráfico 2: Coleta dos dados da Produção da energia gerada na residência 2. Fonte: Autores

A partir de 16 módulos, a terceira residência disponibilizava de 9 módulos para leste e 7 módulos para oeste, a inclinação era de $7^{\circ}$ para todos. O sistema para acompanhar foi o WEG. A potência média da semana foi de $172,13 \mathrm{~W}$, e melhor dia igual as outras residências, com média no dia de $184,36 \mathrm{~W}$, e maior produção as $11 \mathrm{~h}$ como mostrado no Gráfico 3 com valor de 244,26W.

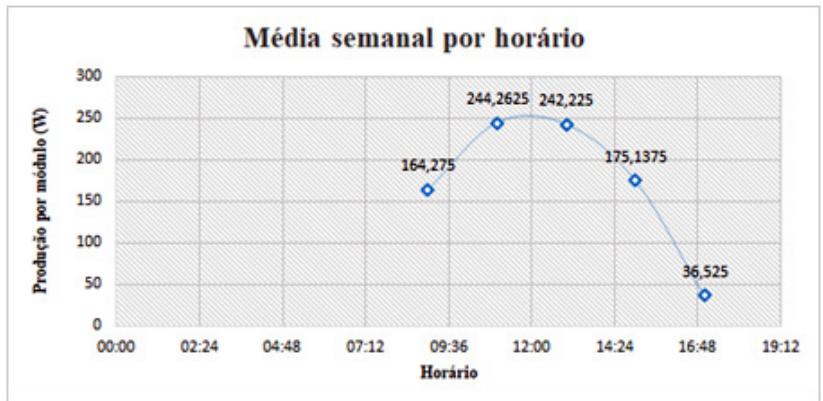

Gráfico 3: Coleta dos dados da Produção da energia gerada na residência 3. Fonte: Autores

A quarta residência teve 26 módulos, com o posicionamento de 14 para leste e 12 para oeste, com $10^{\circ}$ grau de inclinação, monitorado por sistema Fronius. A potência média como mostrado no Gráfico 4 foide $160,65 \mathrm{~W}$, e com o dia 16/09/2019 gerando $174,31 \mathrm{~W}$ sendo a maior potência da semanae com produção máxima de $237,93 \mathrm{~W}$ às $13 \mathrm{~h}$.

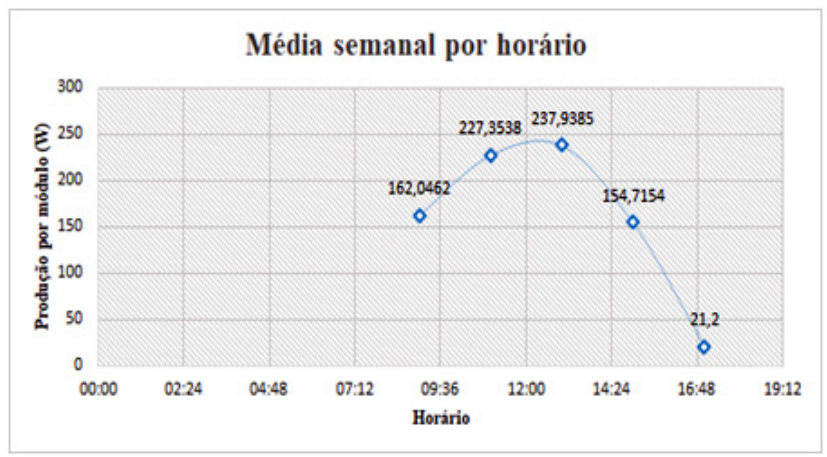

Gráfico 4: Coleta dos dados da Produção da energia gerada na residência 4. Fonte: Autores

O Gráfico 5 foi resultado de uma média da quinta residência onde apresentava 8 módulos todos apontados para o norte, com $11^{\circ}$ de inclinação, e acompanhado pelo sistema Growatt, com potência média de 139,22 W, com melhor rendimento no mesmo dia das outras residências sendo de 144,9 W, maior média de potência de 218,50W às $13 \mathrm{~h}$. Sua geração de potência foi menor devido ao um sombreamento na parte da manhã nos painéis, afetando sua produção.

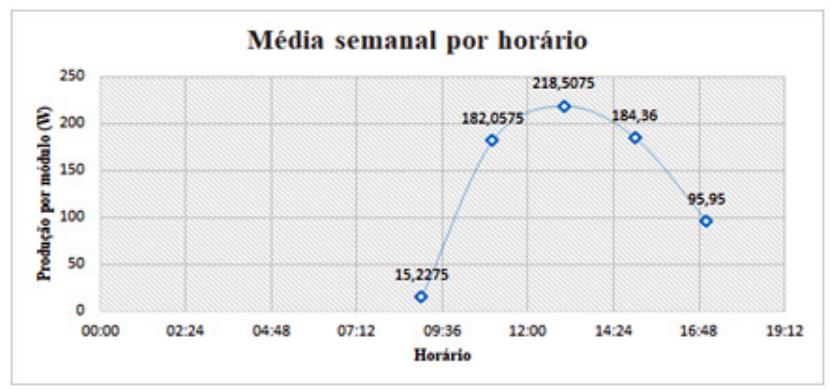

Gráfico 5: Coleta dos dados da Produção da energia gerada na residência 5. Fonte: Autores

Com os resultados obtidos, foi possível observar que a residência com maior eficiência solar foi a primeira casa, com $14^{\circ}$ de inclinação com todos posicionados para o norte e média de 183,30W e geração máxima de potência nos horários 
coletados de 269,37W. Sendo assim, percebe-se que devido à diferença de potência gerada em relação às outras casas, leva a crer que com estas configurações é o ideal para conseguir mais eficiência nesta região.

Constata-se também que o horário de pico se dá em uma margem entre $11 \mathrm{~h}$ ás $13 \mathrm{~h}$, e levando em consideração sua geração de potência ideal de $330 \mathrm{~W}$, a primeira moradia obteve um percentual de rendimento de $77,57 \%$, enquanto a segunda teve $75,90 \%$, e as demais $73,70 \%, 70,49 \%$ e $60,69 \%$.

Vale ressaltar em relação à quinta casa por que teve seus dados alterados devido a um sombreamento que ocorreu durante a parte da manhã no momento em que estava sendo colhidos os dados e além dos painéis estarem com sujeira ${ }^{14}$.

\section{Conclusão}

Por meio da analise dos resultados, conclui-se que para a região de Vianópolis o melhor posicionamento para o módulo fotovoltaico é com sua face voltada para a direção norte, e quanto mais próximo o ângulo de inclinação da latitude, maior será a geração de potência. Observa-se que o horário de pico de irradiação é no período das $11 \mathrm{~h}$ as $13 \mathrm{~h}$ durante o decorrer do dia.

\section{Referencial Bibliográfico}

1. Cabral, Isabelle; Vieira, Rafael. Viabilidade econômica $x$ viabilidade ambiental do uso de energia fotovoltaica no caso brasileiro: uma abordagem no período recente. In: III Congresso Brasileiro de Gestão Ambiental. 2012.

2. ANEEL. Energia solar 3. Disponível em $<$ http://www2.aneel.gov. br/aplicacoes/atlas/pdf/03-Energia_Solar(3).pdf $>$. Acesso em: $10 \mathrm{de}$ Abril de 2019.

3. Groth, Júlio Augusto.; Usina de Geração Fotovoltaica: Custo de Implantação, Operação e Taxa de Retorno do Investimento. Porto Alegre, 2013.

4. MIT. 2015. Integration of Solar Generation in Wholesale Electricity Markets. The Future of Solar Energy, 175-205.

5. Layer Solar. Sistema Fotovoltaico. Disponível em $<$ http://www. layersolar.com.br/?page_id=47>. Acesso em 13 de Outubro de 2019.

6. Nascimento, C. Princípio de Funcionamento da Célula Fotovoltaica. Dissertação de Mestrado apresentada à Escola de Engenharia da Universidade Federal de Lavras, Lavras. 2004. $23 \mathrm{f}$.
7. Sampaio, P. G. V., \& González, M. O. A. 2017. Photovoltaic solar energy: Conceptual framework. Renewable and Sustainable Energy Reviews, 74 (December 2016), 590-601.

8. Souza, A. de, \& Aristone, F. 2017. ESTUDO DA EFICIÊNCIA ENERGÉTICA DE CÉLULAS FOTOVOLTAICAS EM FUNÇÃO DA RADIAÇÃO SOLAR NO CENTRO-OESTE BRASILEIRO. Inter Espaço: Revista de Geografia e Interdisciplinaridade, 2 (7), 115.

9. Vitti, D.C.; Alvares, L.M.; AVALIAÇÃO DA EFICIÊNCIA DOS SISTEMAS FOTOVOLTAICOS. Brasília, 2006.

10. Bortolo, V. A., Souza, A., Goes, G., Martins, M. A., Berghe, M. J., \& Kimura Montanha, G. 2017. Geração de Energia Solar On Grid e Off Grid.6.

11. COGEN, 2012. Inserção a Energia Solar no Brasil. São Paulo, 77.

12. Gradela, M. A.; Rafael, J. G; Energia solar fotovoltaica: Conceitos e Aplicações. 2. ed. São Paulo: Érica, 2012.

13. Blaszczak, V., ANÁLISE DE EFICIÊNCIA DE PAINEL FOTOVOLTAICO COM SISTEMA TRACKER SEGUIDOR SOLAR, Erechim, 2017.

14. Urbanetz Jr, J.; Casagrande Jr, E.; Tiepolo, G. M. Acompanhamento do desempenho do sistema fotovoltaico conectado à rede elétrica do escritório verde da UTFPR. IX Congresso Brasileiro de Planejamento Energético. 2014a.

\section{Gabriel V. Barbosa, Matheus F. S. Alcântara*, Matheus R. G. Araújo, Tiago T. Fonseca, Rosemberg F. N. Rodrigues \& Márcio J. Dias}

Centro Universitário de Anápolis - UniEVANGÉLICA. Avenida Universitária, km 3,5, Centro Universitário, Anápolis, Goiás, Brasil.

*E-mail: matheusrg70@gmail.com 